\title{
Physicochemical Study of Gamma-irradiated Mono Azo Dye in Aqueous Solutions as Liquid Dosimeter
}

\author{
M. El-Kelany \\ National Center for Radiation Research and Technology (NCRRT), Atomic Energy \\ Authority, Cairo, Egypt.
}

\begin{abstract}
QUEOUS solutions of $\mathrm{pH}$ indicator (mono azo dye) Amacid Yellow M (AYM)

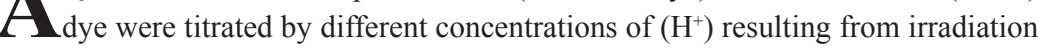
decomposition of trichloroethylene $\left(\mathrm{ClHC}=\mathrm{CCl}_{2}\right)(\mathrm{TCE})$ solution for possible use as an monitoring device (label) for gamma radiation. The titrated solutions were readout spectrophotometrically. These solutions can be used qualitatively as routine indicators in the $0.5-5 \mathrm{kGy}$ range because they have stable change in color for (AYM) from yellow to red at $540 \mathrm{~nm}$ depending on irradiated trichloroethylene $\left[\mathrm{H}^{+}\right]$. The effective dose range exceeds in this technique due to avoiding direct exposure of dye to gamma radiation, utilizing back titration technique followed by color measurements using spectrophotometer. Moreover, the useful measuring range was found to be $5 \mathrm{kGy}$. The solutions can be used qualitatively as routine indicators in the range of 0.5 to $2 \mathrm{kGy}$. Further calculations such as rate of reaction (r) and kinetic constant (k) have been assigned.
\end{abstract}

Keywords: Amacid Yellow M, Trichloroethylene, Gamma ray dosimeter.

\section{Introduction}

Many solutions undergo $\gamma$-irradiation for effective sterilization such as medical solutions, cosmetic lotions, ointments and others that need dose detection. Using liquid dosimeters or labels of the absorbed doses were detected without any absorption extension coefficient corrections. These indicators are based mainly on radiochromic dye (Kovacs et al., 2000; Akhavan et al., 2002 and Butson et al., 2001), pH-indicator dye (Abdel-Fattah et al., 2002). They are not used for quantitative dose measurements while label dosimeters may be used for quantitative dose measurements during radiation processing.

Radiation indicators based on the irradiation induced colour change used for identification of irradiated and unirradiated products in sterilization and food preservation by irradiation (Gafar \&ElAhdal, 2014). Due to their sensitivity towards various influence factors stable to temperature and humidity changes, linearity in dose response is used for quantitative purposes (Shaheen et al., 2013). Indicators such as tetra bromophenol blue can exist in two tautomeric forms having different colors in the dose range from 1 to $8 \mathrm{kGy}$ (Beshir, 2013). Gafar et al.(2014) and Gafar \& El-Ahdal (2015) developed a two new gel dosimetry systems based on the addition of Toluidine blue- $\mathrm{O}$ and fuchsine acid cyanide dye to gelatin, which are useful for radiation processing in the range of $1-150 \mathrm{~Gy}$ and 1-170 Gy; respectively. Aqueous solutions of $\mathrm{pH}$ indicators congo red (CR) and quinaldine red (QR) dyes were titrated by different concentrations of $\left(\mathrm{H}^{+}\right)$resulting from irradiation decomposition of chloral hydrate $(\mathrm{CH})$ solution for possible use as an monitoring device (label) for gamma radiation (El-Kelany \& Ebraheem, 2011).

In the present work, solutions of (AYM) were titrated by irradiated TCE that have different doses were studied for use in low-dose dosimetry through back titration followed by color measurements using spectrophotometer (Indirect irradiation technique). 


\section{Experimental}

\section{Materials}

Amacid Yellow M, (monosodium salt of 4-msulphophenyl - azodiphenyl amine) is an acidic azo dye, of molecular weight: $375.38 \mathrm{~g} / \mathrm{mol}$, molecular formula $\mathrm{Cl}_{8} \mathrm{H}_{14} \mathrm{~N}_{3} \mathrm{NaO}_{3} \mathrm{~S}$, purchased from Sigma-Aldrich, Germany (Scheme 1).

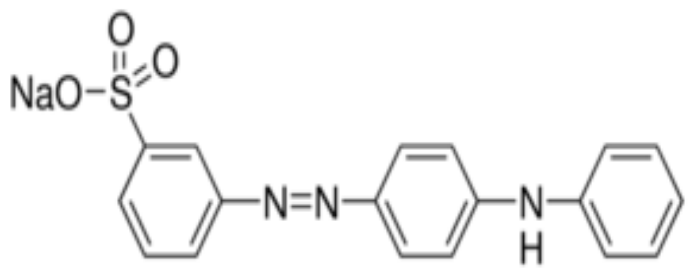

Amacid Yellow M

Scheme 1

Apparatus

Irradiation was conducted using a ${ }^{60} \mathrm{Co}$ gamma chamber $4000 \AA$ (product of India). The absorbed dose rate is $1.429 \mathrm{kGy} / \mathrm{h}$. The absorption spectra of the unirradiated and irradiated solutions of both dyes were measured using a UV4-visible spectrophotometer. The irradiation of chloral hydrate done using several ampoules of PCE $5 \mathrm{ml}$ each exposed to different doses. After irradiation, titration proceeds $(0.1 \mathrm{ml}$ of irradiated TCE solution $[0.5 \mathrm{~N}]$ with $2 \mathrm{ml}$ of dye solution).

\section{Results and Discussion}

\section{Absorption spectra}

Depending on avoiding exposure of AYM pH indicator proceed back titration with irradiated trichloroethylene $(0.5 \mathrm{~N})$ applying different doses of $\gamma$-irradiation $(0.5,0.7,1,1.5,2,3,5 \mathrm{kGy})$ and using the irradiated resulting $\left[\mathrm{H}^{+}\right]$concentrations in titration of $0.25 \mathrm{phr}$ concentration for dye. The absorption spectra of the unirradiated and irradiated films and gels were measured in the wavelength range $200-800 \mathrm{~nm}$. The absorption spectra of the AYM solution and (0.5phr AYM) were recorded before and after irradiation at different doses (0-0.7 kGy) as shown in Fig. 1. Upon irradiation, the amplitude of the peak was found to be decreased gradually with increasing the doses ofgamma rays on TCE solutions, starting from $0.5 \mathrm{kGy}$ to $5 \mathrm{kGy}$ as shown in Fig. 2. This is due to the consequent lowering of $\mathrm{H}^{+}$ concentration caused by the $\mathrm{HCl}$ generated from radiolysis of trichloroethylene. AYM dye reacts with the consequent $\left[\mathrm{H}^{+}\right]$increase according to absorbed dose which leads to color changes and a decrease in the peak intensity at $430 \mathrm{~nm}$ (yellow) and an increase in the peak intensity at $550 \mathrm{~nm}$ (red).

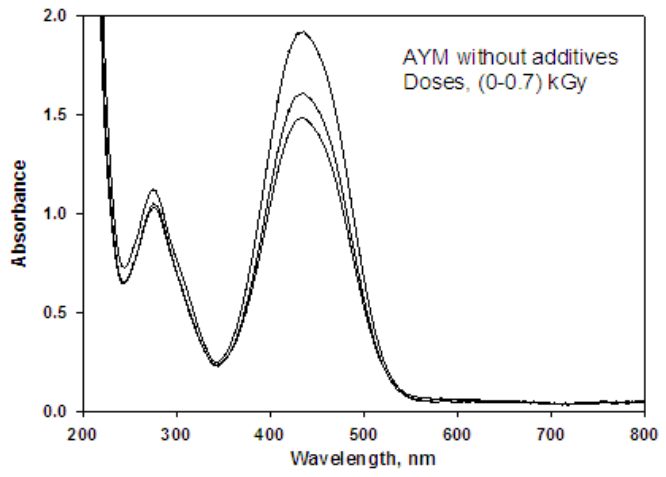

Fig. 1. The absorption spectra of AYM aqueous solution unirradiated and irradiated to different absorbed doses.

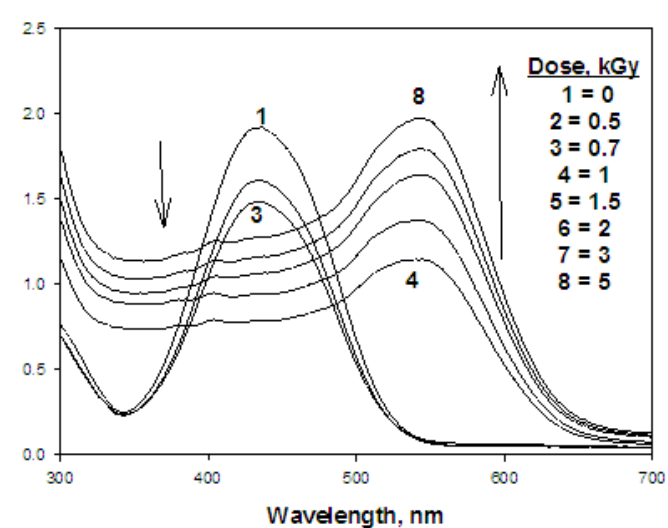

Fig. 2. The absorption spectra of AYM -TCE aqueous solution unirradiated and irradiated to different absorbed doses.

\section{Response curves}

The response curves of [AYM/TCE] solutions at different doses are shown in Fig. 3. The response was established in terms of change in relative percentage of the absorbance $\left[\left(\mathrm{A}_{\mathrm{i}} / \mathrm{A}_{\mathrm{o}}\right) \times 100\right]$, (where $\mathrm{A}_{\mathrm{o}}$ and $\mathrm{A}_{\mathrm{i}}$ are the relative absorbencies of unirradiated solutions, respectively) for two peaks at 430 and 550nm against the absorbed dose. It can be noticed that both responses have the same trend in the range of $0.5 .-5 \mathrm{kGy}$ with different slope.

\section{Radiolysis of TCE}

Solvents, particularly those which contain no hydrogenatomare consideredliquidorganichalides and radiolytically oxidizing. Thus, irradiated TCE is oxidizing in that it is a source of chlorine atoms. 


$$
\begin{array}{ll} 
& 2 \mathrm{C}_{2} \mathrm{Cl}_{3} \mathrm{H}_{\rightarrow} 2 \mathrm{Cl}+2 \cdot \mathrm{CCl} 2+\mathrm{H}^{\prime} \\
& 2 \cdot \mathrm{Cl} \underset{\mathrm{Cl}_{2}}{\rightarrow} \\
\mathrm{H}^{\cdot}+\mathrm{Cl}^{\cdot} \rightarrow \mathrm{HCl} \\
\mathrm{H}^{\cdot}+\mathrm{H}^{\cdot} \rightarrow \mathrm{H}_{2}
\end{array}
$$

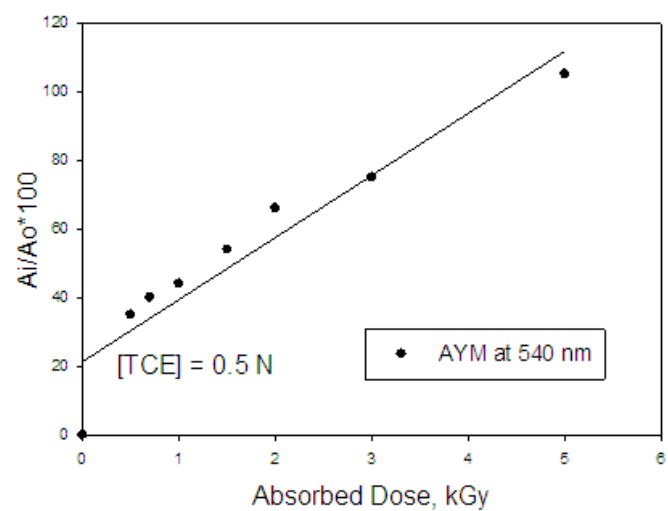

Fig. 3. Change of response of AYM-TCE solutions $\left[(\mathrm{Ai} / \mathbf{A o})^{*} \mathbf{1 0 0}\right]$ as a function of absorbed dose.

\section{Calculation of concentration of $\mathrm{H}^{+}$}

The effect of $\left[\mathrm{H}^{+}\right]$at different $\mathrm{pH}$ solutions of AYM at a dose range from 0.5 to $5 \mathrm{kGy}$ has been studied. The change in the $\mathrm{pH}$ as a function of the absorbed dose can lead to the increase of the acidity of the dye with the decrease of the $\mathrm{pH}$ (acid-base titration). This phenomenon is a new development for the excessive presence of $\mathrm{H}^{+}$in the medium. Figure 4 shows the total amount of acid formed in solutions of both dyes containing trichloroethylene as a function of the absorbed dose. It can be seen that the amount of $\left[\mathrm{H}^{+}\right]$ increases gradually with increasing the absorbed dose.

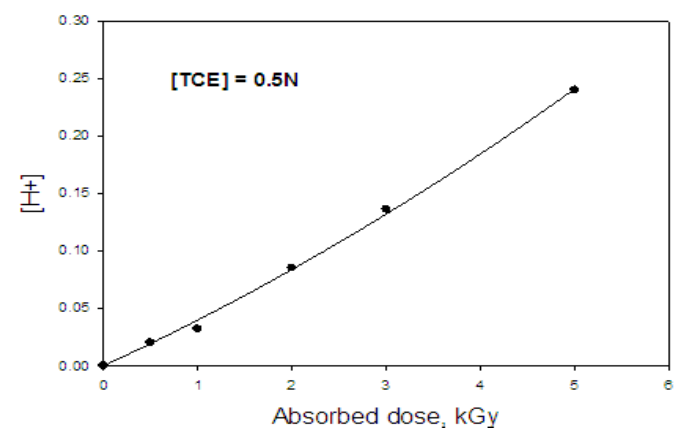

Fig. 4. Variation of $\left[\mathrm{H}^{+}\right]$in AYM solutions as a function of the absorbed dose.

\section{Kinetics of $\mathrm{H}^{+}$formation}

In these solutions (AYM containing TCE), the $\mathrm{H}^{+}$is formed due to the irradiation of TCE. This reaction may be considered as follows:

$$
\mathbf{a}[\mathrm{TCE}] \rightarrow\left[\mathrm{H}^{+}\right]
$$

where, $\left[\mathrm{H}^{+}\right]$is the concentration of radiationformed hydrogen ions, the rate law of this reaction may be written as follows:

$$
\begin{array}{ll} 
& \mathrm{d}\left[\mathrm{H}^{+}\right] / \mathrm{dt}=\mathrm{k}\left[\mathrm{H}^{+}\right]^{\mathrm{a}} \\
\text { or } & \text { rate of reaction }=\mathrm{k}\left[\mathrm{H}^{+}\right]^{\mathrm{a}}
\end{array}
$$

where $\mathbf{a}$ is the order of the reaction (relationship between the concentration of $\mathrm{H}^{+}$to the rate of reaction) and $\mathrm{d}\left[\mathrm{H}^{+}\right] / \mathrm{dt}$ is the rate of reaction. The order a can be determined using the initial slopes method. Plotting change in concentration of $\mathrm{H}^{+}$ (on log-log scale) against various times gives the rate and order of reaction from the slope shown in Fig. 5. Straight line was obtained, slope is 0.502 for hydrogen concentration which detected by dye solution of AYM, the order of this reaction is $1 / 2$. Accordingly, the rate law of $\left[\mathrm{H}^{+}\right]$in this acid-base titration reaction, may be expressed as follows:

$$
\begin{array}{ll} 
& \mathrm{d}\left[\mathrm{H}^{+}\right] / \mathrm{dt}=\mathrm{k}\left[\mathrm{H}^{+}\right]^{1 / 2} \\
\text { or } & \mathrm{d}\left[\mathrm{H}^{+}\right] / \mathrm{dD}=\mathrm{k}\left[\mathrm{H}^{+}\right]^{1 / 2}
\end{array}
$$

Figure 6 shows the increase of concentration of $\left[\mathrm{H}^{+}\right]^{1 / 2} / 2$, as a function of the absorbed dose. Straight lines were obtained in accordance with a half-order kinetics (El-Kelany, 1997). The kinetic constant, $\mathrm{k}$, is obtained as the slope of straight line mentioned above. The values of $\mathrm{k}$ for AYM solution are $9.1 \times 10^{-3}\left(\mathrm{~mol} . \mathrm{L}^{-1}\right)^{1 / 2} \mathrm{~Gy}^{-1}$.

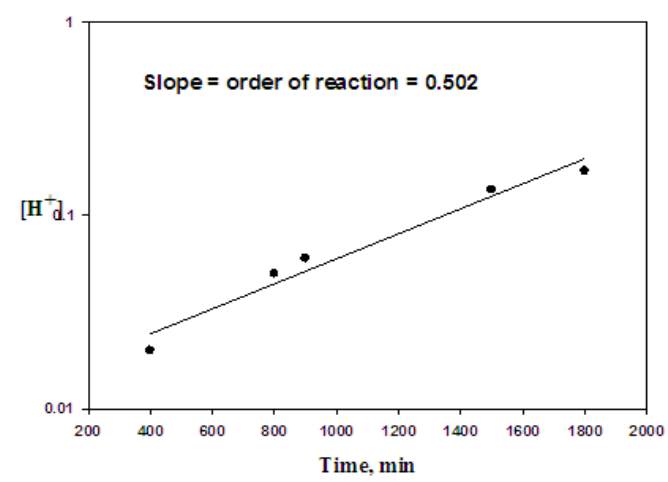

Fig. 5. Variation of $[\mathrm{H}+]$ in aqueous solutions of (AYM -TCE) as a function of time.

Over view on this technique used

The effective dose range exceeds in this technique due to avoiding the exposure of dye to gamma radiation. 


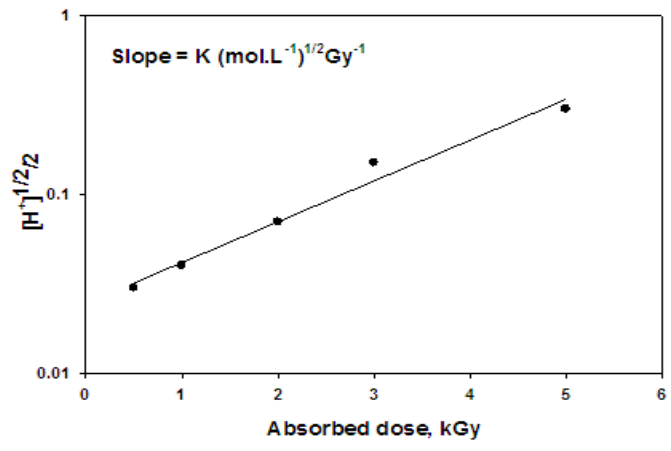

Fig. 6. Increase of concentration of acid in of (AYM -TCE) solutions versus the absorbed dose.

\section{Conclusion}

This approach for preparing new radiation sensitive indicators by titrating acid-sensitive dyes with irradiated trichloroethylene may be useful. These solutions can be used qualitatively as routine indicators in the $0.5-5 \mathrm{kGy}$ range because they have stable change in color for (AYM) from yellow to red at $540 \mathrm{~nm}$ depending on the irradiated trichloroethylene $\left[\mathrm{H}^{+}\right]$. Using the phenomenon of generated $\mathrm{HCl}$ from TCE under irradiation, hydrogen ion concentrations as a function of irradiated time was used to calculate the kinetic constant of the reaction $\left(\approx 9.1 \times 10^{-3}\right.$ $\left.\left(\mathrm{mol} \cdot \mathrm{L}^{-1}\right)^{1 / 2} \mathrm{~Gy}^{-1}\right)$.

Declaration of interest: There are no conflicts of interest. The author is the sole responsible for the content and writing of the paper.

Acknowledgment: This work was financially supported by National Center for Radiation Research and Technology (NCRRT), Atomic Energy Authority (EAEA), Cairo, Egypt for basic research in the field of radiation technology applications.

\section{References}

Abdel-Fattah, A.A., Hegazy, E.S.A. and Ezz El-Din, H. (2002) Radiation chemical formation of $\mathrm{HCl}$ in Poly (vinyl butyral) films containing chloral hydrate for use in radiation dosimetry. Int. J. Polymeric Materials, 51, 413.

Akhavan, A., Sohrabpour and Sharifzadeh, M. (2002) Preparation of a new chemical radiochromic film dosimeter. Radiat. Phys. Chem. 63, 77.
Beshir, W.B. (2013) Radiation sensitive indicator based on tetrabromophenol blue dyed poly (vinyl alcohol). Radiat. Phys. Chem. 86, 129-135.

Butson, M., Chueng, J. and Yu., P.K.N. (2001) GafChromic radiochromic dosimetery films information. Physis in Medicin and Biology, 46, 27.

El-Kelany, M. (1997) Physico-chemical studies on some prepared polymeric films used for radiation dosimetry, Faculty of Science, Chemistry Department, Ain Shams University.

El-Kelany, M. and Ebraheem, S. (2011)Physicochemical study of gamma irradiated $\mathrm{pH}$ - Indicator. Egypt. J. Rad. Applic. 24(2), 335-343.

Gafar, S.M and El-Ahdal, M.A. (2014) Dosimetric characteristics of 2,6 di-nitro phenol for high dose dosimetry, Dyes Pigm. 109, 67-71.

Gafar, S.M. and El-Ahdal, M.A. (2015) Radiochromic fuchsine-gel and its possible use for low dosimetry applications, Adv. Polym. Technol. http://dx.doi. org/10.1002/adv.21538.

Gafar, S.M., El-Kelany, M.A., El-Ahdal, M.A. and ElShawadfy, S.R. (2014) Toluidine blue O-gelatin gel dosimeter for radiation processing, Open J. Polym. Chem. 456-61.

Kovacs, A., Baranyai, M., Wojnarovits, L., McLaughlin, W.L., Miller, S.D., Miller, A., Fuochi, P.G., Lavalle, M. and Slezsak, L. (2000) Application of the sunna dosimeter film in gamma and electron beam radiation processing. Radiat. Phys. Chem. 57, 691.

Shaheen, A., Taqmeem, H., Amir, S. and Qamar, I. (2013) The feasibility of reactive dye in PVA films as high dosimeter, Basic Appl. Sci. 9, 420-423.

(Received $1 / 11 / 2017$; accepted $10 / 1 / 2018$ ) 


\section{دراسـه فيزوكيميائه على محاليل صبغه احاديه الازو للاستخدام ككاشف اشعاعى مشيزة الكيلانى المركز القومى لبحوث وتكنولوجيا الإشعاع ـ هيئة الطاقة الذرية المصرية ـ القاهرة ـ مصر.}

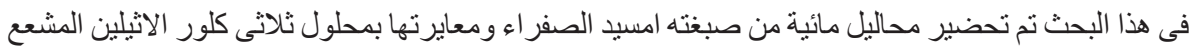

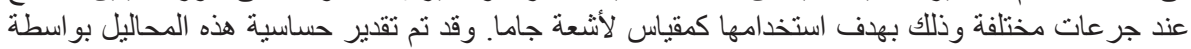

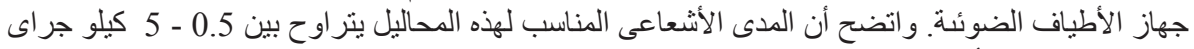

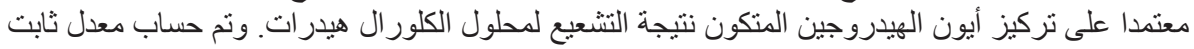
حركة التفاعل. - معنى تركيز 